(c) 2020 Universidad Nacional Autónoma de México, Facultad de Estudios Superiores Zaragoza.

Este es un artículo Open Access bajo la licencia CC BY-NC-ND (http://creativecommons.org/licenses/by-nc-nd/4.0/).

TIP Revista Especializada en Ciencias Químico-Biológicas, 23: 1-13, 2020.

https://doi.org/10.22201/fesz.23958723e.2020.0.234

\title{
Características comunes de las chaperonas pequeñas y diméricas
}

\author{
Teresa Nava Ramírez y Wilhelm Hansberg* \\ Departamento de Biología Celular y del Desarrollo, Instituto de Fisiología Celular, \\ Universidad Nacional Autónoma de México, UNAM. Circuito exterior s/n, Ciudad \\ Universitaria, Colonia UNAM, Alcaldía Coyoacán, C.P. 04510, Ciudad de México, México. \\ E-mails: tnava@ifc.unam.mx,whansberg@ifc.unam.mx*
}

\begin{abstract}
RESUMEN
Las chaperonas moleculares constituyen un mecanismo importante para evitar la muerte celular provocada por la agregación de proteínas. Las chaperonas independientes del ATP son un grupo de proteínas de bajo peso molecular que pueden proteger y ayudar a alcanzar la estructura nativa de las proteínas desplegadas o mal plegadas sin necesidad de un gasto energético. Hemos encontrado que el dominio C-terminal de las catalasas de subunidad grande tiene actividad de chaperona. Por ello, en esta revisión analizamos las características más comunes de las chaperonas pequeñas y más estudiadas como: $\alpha$ B-cristalina, Hsp20, Spy, Hsp33 y Hsp31. En particular, se examina la participación de los aminoácidos hidrofóbicos y de los aminoácidos con carga en el reconocimiento de las proteínas sustrato, así como el papel que tiene la forma dimérica y su oligomerización en la actividad de chaperona. En cada una de esas chaperonas revisaremos la estructura de la proteína, su función, localización celular e importancia para la célula.
\end{abstract}

Palabras clave: chaperonas moleculares, independientes de ATP, mecanismo de acción, dímero, oligomerización.

\section{Common characteristics of small dimeric chaperones}

\begin{abstract}
Molecular chaperones constitute an important mechanism to prevent cell death caused by protein aggregation. ATPindependent chaperones are a group of low molecular weight proteins that can protect or restore the native structure of unfolded or mis-folded proteins without expenditure of energy. Because we recently found that the C-terminal domain of large-size subunit catalases has a chaperone activity, we are reviewing common characteristics of the most studied low molecular size chaperones, such as $\alpha \mathrm{B}$-crystalline, Hsp20, Spy, Hsp33 and Hsp31. We particularly examine the participation of hydrophobic and charged amino acid residues in protein substrate recognition and the role of dimer formation and its oligomerization in the molecular chaperone activity. We review for each of these molecular chaperones its protein structure, its cellular function and localization, and its importance for the cell.

Keywords: molecular chaperones, ATP-independent, mechanisms of action, dimers, oligomerization.
\end{abstract}




\section{INTRODUCCIÓN}

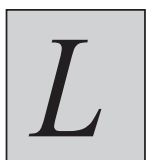

a agregación de proteínas debido a la pérdida de la estructura funcional es una de las causas del daño que puede conducir a la muerte celular. Las células tienen diferentes mecanismos para contrarrestar el daño inminente. Uno de los más importantes lo constituyen las chaperonas moleculares que se pueden definir como cualquier proteína que interactúa, estabiliza o ayuda a otra proteína malplegada o parcialmente desplegada a adquirir su conformación nativa (Hartl \& Hayer-Hartl, 2009). Las chaperonas también son esenciales durante la traducción para el plegamiento de novo de las proteínas, para el transporte a través de las membranas de los diferentes compartimentos celulares, en la degradación de las proteínas agregadas y en la retención en el citoplasma de algunos factores de transcripción (Hall, 2019; Hartl, Bracher \& Hayer-Hartl, 2011; Kriegenburg et al., 2014; Morimoto, 2002).

Inicialmente fueron descritas como proteínas de respuesta al estrés calórico (Heat Shock Proteins, HSP), pero actualmente se sabe que pueden ser inducidas con diferentes tipos de estrés, como: el osmótico, el oxidante, el frío, o la falta de nutrientes, entre otros (Hartl et al., 2011). Sin embargo, no todas las chaperonas se inducen en condiciones de estrés. Las características que las describen de mejor manera son: su presencia en diferentes compartimentos celulares así como en el medio extracelular, su abundancia y gran capacidad para interaccionar con diversas proteínas sin que la interacción dependa de dominios o secuencias específicas (Hartl et al., 2011; Macario, Conway de Macario \& Cappello, 2013).

Las chaperonas moleculares se pueden dividir según su dependencia de energía en dos grandes grupos: las que dependen del ATP y las independientes del ATP(Hiller \& Burmann, 2018; Suss \& Reichmann, 2015). Las chaperonas dependientes del ATP emplean ciclos de hidrólisis del ATP junto con grandes cambios conformacionales para reconocer, replegar y liberar sus proteínas sustrato. Son proteínas de peso molecular alto y forman oligómeros para realizar su actividad de chaperona; los ejemplos más estudiados son Hsp60 (GroEL/ES), Hsp70/ Hsp110 (DnaK), Hsp104 (ClpB) y Hsp90 (HtpG) (Hartl et al., 2011; Hiller \& Burmann, 2018).

Las chaperonas independientes del ATP tienen en común la característica de prevenir la agregación y en algunos casos ayudar a plegar las proteínas sin necesidad de recurrir a un gasto energético.Además, pueden presentar alguna actividad catalítica de manera independiente a su función de chaperona, como la de proteasa o de isomerasa (Hall, 2019; Suss \& Reichmann, 2015). Estas chaperonas constituyen un grupo diverso y ubicuo de proteínas que tienen un peso molecular entre los 12 a los 43 kDa (Jaspard \& Hunault, 2016).

Debido a su bajo peso molecular, dichas chaperonas han sido muy estudiadas para tratar de dilucidar su mecanismo de acción, ya que permiten el uso de técnicas como NMR, SAXS, FRET y espectrometría de masas combinada con métodos computacionales para su estudio (Suss \& Reichmann, 2015). El mecanismo de acción de estas chaperonas es similar entre ellas a pesar de la diversidad estructural que presentan. Se basa principalmente en la unión de superficies hidrófobas flexibles con las superficies hidrófobas expuestas de la proteína sustrato, junto con interacciones de alta afinidad combinadas con una dinámica de baja afinidad para estabilizar la interacción(Webster, Darling, Uversky \& Blair, 2019). La forma dimérica favorece la flexibilidad de la estructura de las chaperonas volviéndolas más dinámicas (Santhanagopalan et al., 2018; Suss \& Reichmann, 2015) y en algunos casos, se pueden organizar en oligómeros de dímeros (Saio, Kawagoe, Ishimori \& Kalodimos, 2018; Santhanagopalan et al., 2018).

Recientemente hemos descubierto que el dominio C-terminal de las catalasas de subunidad grande tienen actividad de chaperona (Nava Ramírez, 2017; Nava Ramírez \& Hansberg, 2020). Este dominio C-terminal se parece en estructura a las chaperonas DJ-1 y Hsp31. En el tetrámero de la catalasa los dominios C-terminal están relacionados de manera que forman dos dímeros. Estamos interesados en dilucidar el mecanismo molecular de la actividad de chaperona de esos dominios y si funcionan como dímeros. Por otro lado, en algunas chaperonas de bajo peso molecular se ha visto la importancia para su actividad de algunos aminoácidos hidrofóbicos y de algunos aminoácidos con carga que se encuentran en la superficie de la proteína. El motivo de esta revisión es analizar en las chaperonas de bajo peso molecular la participación de los aminoácidos hidrofóbicos y de los aminoácidos con carga en el reconocimiento de las proteínas sustrato, así como el papel de la forma dimérica y de su oligomerización en la actividad de chaperona. Revisaremos las chaperonas más estudiadas como son: las chaperonas pequeñas del estrés calórico (sHSP por sus siglas en inglés), la $\alpha \mathrm{B}$-cristalina y la Hsp20, las bacterianas Spy y Hsp33 y las ubicuas Hsp31. Estas chaperonas forman parte de una red de defensa de las células para el mantenimiento de la homeostasis proteica.

\section{aB-CRISTALINA (HsPB5)}

La $\alpha$-Básico-cristalina ( $\alpha \mathrm{B}$-cristalina, $\alpha \mathrm{Bc})$, también llamada HspB5, es una chaperona de $20 \mathrm{kDa}$ perteneciente a la superfamilia de las sHSP en los mamíferos (GruvbergerSaal \& Parsons, 2006). Esta proteína se asocia en solución principalmente como un dímero estable, el cual presenta una mayor actividad de chaperona que el monómero (Muranova \& Gusev, 2018). A partir del dímero se pueden formar multímeros que llegan a ser hasta de 40 subunidades (Figura $1 \mathrm{~A}-\mathrm{C}$ ), ya sean homo-oligómeros o hetero-oligómeros con otras sHSP como son las $\alpha \mathrm{A}$-cristalina ( $\alpha \mathrm{Ac}$ ), Hsp27, HspB6 y HspB8. En el cristalino del ojo la interacción $\alpha \mathrm{Ac} / \alpha \mathrm{Bc} 3: 1$ es la más abundante (Boelens, 2014). 

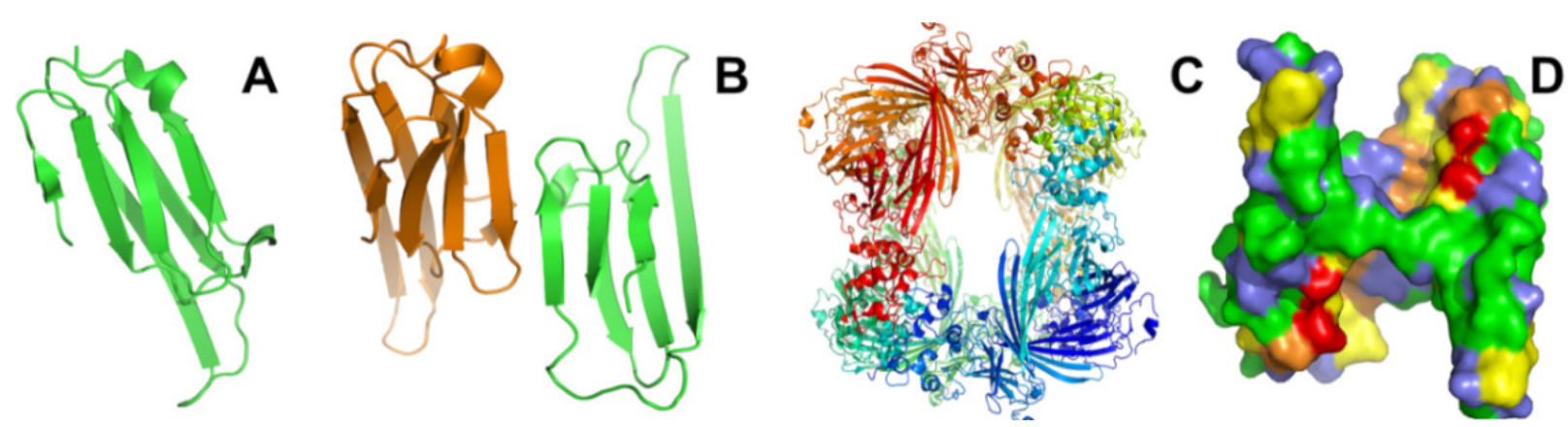

Figura 1. Estructura cristalográfica del dominio sHSP de la chaperona aB-cristalina de humano. A) Monómero. B) Dímero. C) Oligómero de 24 subunidades, se forma como un dodecámero de dímeros. D) Superficie del dímero. Los aminoácidos hidrofóbicos están marcados en amarillo y los residuos hidrofóbicos que participan en la interacción con el sustrato en color naranja. Los aminoácidos con carga están marcados en verde y los residuos con carga que participan en la interacción con el sustrato en rojo. Los demás aminoácidos se muestran en azul. Código de acceso del PDB: 2wj7 para el panel A, B y D; 2ygd para panel C (Bagnéris et al., 2009; Braun et al., 2011).

La $\alpha \mathrm{Bc}$ se expresa también en los tejidos de diferentes órganos como: el pulmón, el estómago, el colon, la vejiga, el cerebro, el corazón, el músculo esquelético, el hígado, el bazo y el timo (Klemenz, Andres, Fröhli, Schäfer \& Aoyama, 1993). En el cristalino del ojo la $\alpha \mathrm{Bc}$ es una de las proteínas más abundantes junto con la $\alpha$ A-cristalina, ambas representan el $\sim 40 \%$ de las proteínas del citoplasma y su estructura confiere la transparencia al cristalino (Gruvberger-Saal \& Parsons, 2006). Anivel celular se localiza principalmente en el citoplasma (Brodehl et al., 2017), en la mitocondria (Jin et al., 2008), en la membrana plasmática y en el núcleo (Vos, Kanon \& Kampinga, 2009). Durante el estrés por calor la $\alpha \mathrm{Bc}$ se traslada a las estructuras subnucleares conocidas como puntos de "splicing" nuclear, que son zonas donde se realiza el procesamiento del mRNA (Vos et al., 2009). La función que realiza en este sitio es favorecer el plegamiento de las proteínas desnaturalizadas, así como el transporte de la proteína FBX4, una proteína que se requiere para la ubiquitinación de las proteínas y su degradación (Den Engelsman et al., 2004; Vos et al., 2009). La localización en esta zona no depende de la interacción con el DNA o el RNA, sino que se asocia sólo con otras proteínas que están presentes en ese sitio (Den Engelsman et al., 2004).

La estructura de esta chaperona es característica de las sHSP, que en la $\alpha \mathrm{Bc}$ del humano está compuesta de la región $\mathrm{N}$-terminal variable (NTR), que va del aminoácido 1 al 68; el dominio $\alpha$-cristalina (ACD), que va del residuo 69 al 150, y la región C-terminal (CTR), del aminoácido 151 al 175 (Dimauro, Antonioni, Mercatelli \& Caporossi, 2017). El dominio ACD presenta una estructura de sandwich compuesta por ocho cadenas $\beta$ antiparalelas conectadas por un bucle interdominio(Figura 1A, B). Las cadenas $\beta 6 / \beta 7$ forman la interface de la forma dimérica (Bagnéris et al., 2009). En la región CTR hay un motivo IXI/V (I-P-I/V) que también se encuentra en otras sHSP, que tiene la capacidad de interaccionar con el surco formado entre las cadenas $\beta 4 / \beta 8$ del ACD de otro dímero para la formación de los oligómeros (Dimauro et al., 2017; Liu et al., 2018).

La principal función de $\alpha \mathrm{Bc}$ es prevenir la agregación de otras proteínas, como la $\alpha$-sinucleína localizada en el cerebro o la proteína Titin en el corazón, entre otras (Boelens, 2014). La zona de interacción con los agregados amiloides incluyen los aminoácidos K90, K92, V93, L94, I124, T134, S135, S136 y L137, pertenecientes a las $\beta 4 / \beta 8$, que son también el sitio de interacción con el dominio C-terminal de la proteína que favorece la oligomerización (Liu et al., 2018) (Figura 1 D). Se ha propuesto que el mecanismo de regulación de la actividad de chaperona de esta proteína en los diferentes tejidos es a través de la auto-inhibición por oligomerización, ya que los multímeros presentan una baja actividad de chaperona en condiciones normales, mientras que en el estrés se favorece la disociación de los multímeros en dímeros, dejando libre el surco de las cadenas $\beta 4 / \beta 8$, aumentando así su actividad de chaperona (Liu et al., 2018).

\section{HsP20 (HsPB6)}

La Hsp20, también conocida como HspB6, es una chaperona de $17 \mathrm{kDa}$ perteneciente a la familia de chaperonas Hsp20. Esta familia está ampliamente distribuida en procariontes y en eucariontes. Ha sido estudiada principalmente en mamíferos (Li, Xiao, Zhou, Hu \& Yang, 2017).

A diferencia de otras sHSP, la HspB6 humana no forma oligómeros grandes sino que forma únicamente dímeros en solución, cuya formación no depende de su concentración o de su estado de fosforilación (Weeks et al., 2014). Aunque en la rata se ha observado que se forman oligómeros de dos tipos (van de Klundert et al., 1998): la forma dimérica que presenta actividad de chaperona comparable con otras sHSP y las formas oligoméricas que tienen baja actividad de chaperona 
(Dreiza et al., 2010; van de Klundert et al., 1998). La HspB6 puede interaccionar con la HspB5 o con la HspB1 y formar hetero-oligómeros que pueden ir de los 100 a los $300 \mathrm{kDa}$. Esta oligomerización depende de la temperatura y del estado de fosforilación de las sHSP (Bukach, Seit-Nebi, Marston \& Gusev, 2004; Seit-Nebi \& Gusev, 2009). Por otro lado, la formación de hetero-oligómeros regula la actividad de las otras sHSP: en el caso de los oligómeros de HspB1 se vuelven más específicos hacia un sustrato, mientras que en el caso de los oligómeros de HspB5 aumentan su actividad, debido a que son especies más pequeñas que sus homo-oligómeros (Mymrikov et al., 2019).

HspB6 se localiza principalmente en el citoplasma (Rembold \& Zhang, 2001), aunque su localización cambia con el estrés. Por ejemplo, en condiciones de isquemia, migra del citoplasma a las miofibrillas (Golenhofen, Perng, Quinlan \& Drenckhahn,
2004) y con la inhibición del proteosoma, se transfiere al citoesqueleto de actina (Verschuure et al., 2002). Esto sugiere que protege la estructura celular a través de su interacción con los componentes del citoesqueleto (Li et al., 2017). HspB6 está asociada con diferentes tejidos en los que el nivel de su expresión suele ser alto, como en los tejidos del sistema cardiovascular, en el músculo esquelético, en el músculo liso y en el cerebro (Edwards, Cameron \& Baillie, 2011). Se ha observado que la concentración de la HspB6 está aumentada en la sangre de pacientes con enfermedades vasculares, ya que inhibe la agregación de las plaquetas (Niwa, Kozawa, Matsuno, Kato \& Uematsu, 2000).

La HspB6 humana es una chaperona de 160 residuos (Figura $2 \mathrm{~A}-\mathrm{C}$ ), que presenta una estructura característica de las sHSP, con un dominio conservado ACD rígido (del residuo 61 al 146),
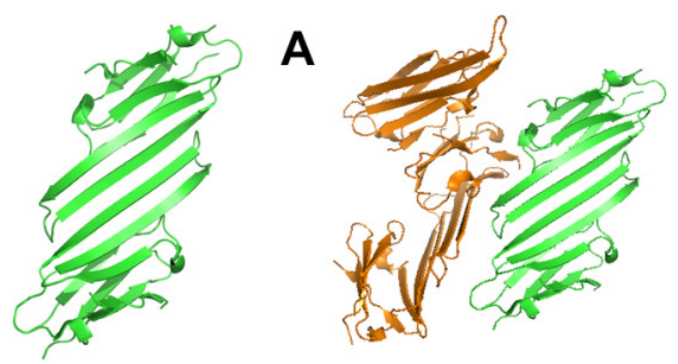

B
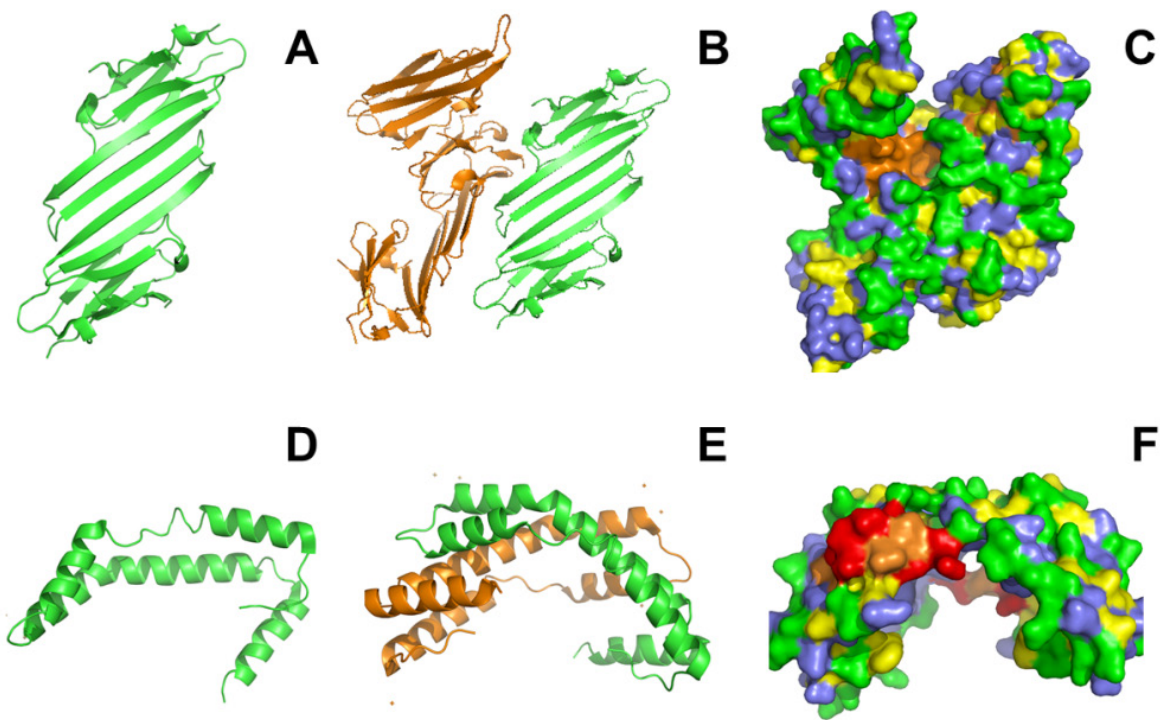

E
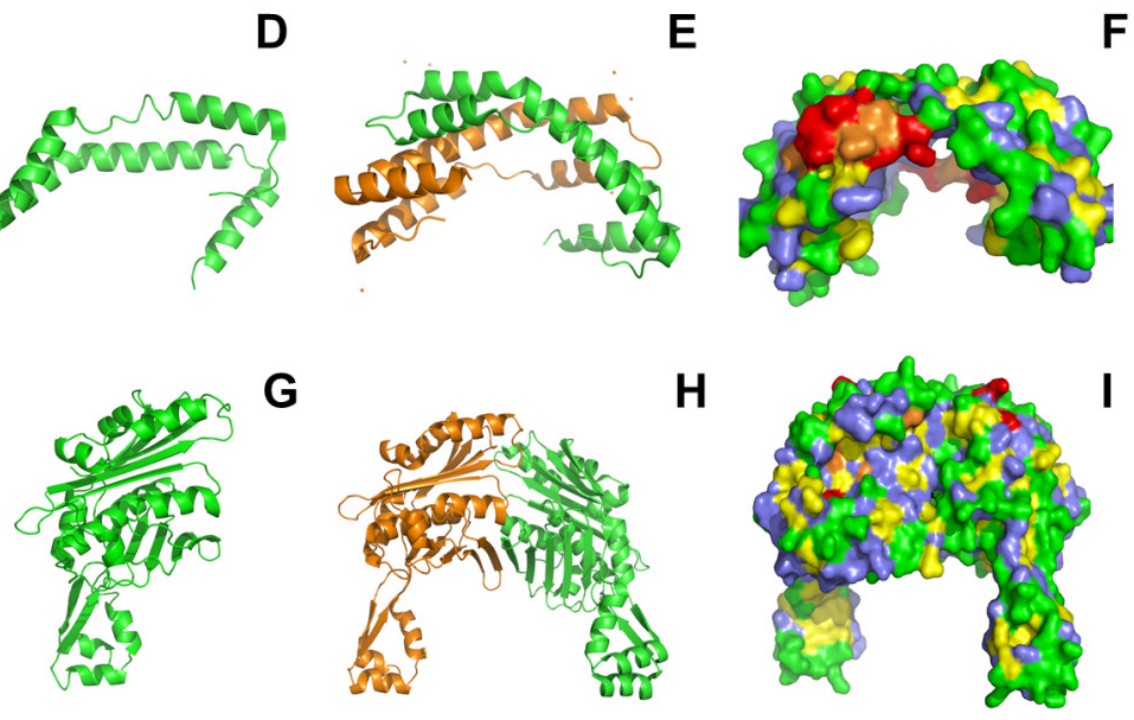

Figura 2. Estructura cristalográfica de la chaperona Hsp20, Spy y Hsp33. Estructuras de Hsp20 o HspB6 de humano A) Monómero. B) Dímero. C) Superficie del dímero. HspB6 puede formar hetero-oligómeros al interaccionar con la HspB5 o con la HspB1, estos oligómeros pueden ir de los 100 a los 300 kDa (Seit-Nebi \& Gusev, 2009), sin embargo, no hay estructura cristalográfica de estos. Estructuras de Spy de $E$. coli D) Monómero. E) Dímero. F) Superficie del dímero. Spy es una proteína dimérica, no se ha observado que forme oligómeros. Estructuras de Hsp33 de Bacillus subtilis. G) Monómero. H) Dímero. I) Superficie del dímero. Hsp33 es una chaperona dimérica que en su estado oxidado activo puede formar especies oligoméricas con mayor actividad que el dímero (Akhtar et al., 2004), sin embargo, no hay estructura cristalográfica de estas especies. Los aminoácidos hidrofóbicos están marcados según lo indicado en la Figura 1. Código de acceso del PDB: 5lum para los paneles A, B y C (Sluchanko et al., 2017), 3039 para los paneles D, E y F (Quan et al., 2011), 1vzy para los paneles G, H e I (Janda et al., 2004). 
flanqueado por la región NTR (del residuo 1 al 60) variable y el dominio CTR (del residuo 147 al 160) (Fan \& Kranias, 2010). Una característica importante de esta chaperona es que su región CTR no presenta el motivo de anclaje IXI/V necesario para la formación de los oligómeros y del dímero en las sHSP (Heirbaut, Beelen, Strelkov \& Weeks, 2014). La región CTR no presenta similitud con la secuencia canónica para las sHSP, en vez de ello, cuenta con una secuencia rica en prolina y alanina (Weeks et al., 2014). La dimerización de la HspB6 ocurre por la interacción del surco hidrofóbico de las cadenas $\beta 4 / \beta 8$ con un motivo tripéptido (IPVPV) de la región NTR de otro monómero de la HspB6, que suple la ausencia del motivo de anclaje IXI/V. Esta interacción se pude llevar a cabo con otras sHSP para formar complejos (Heirbaut et al., 2014; Weeks et al., 2014).

La interacción de la HspB6 con las proteínas parcial o completamente desnaturalizadas se realiza con los residuos I88, V90, V99, V132, S134 y L156 de las cadenas $\beta 4 / \beta 8$, como en otras sHSP (Fuchs et al., 2009). Además, la región NTR es importante para la actividad de chaperona, ya que la eliminación total o parcial de los residuos del 21 al 30 y del 41 al 60 disminuye su actividad. Por otro lado, la eliminación de los residuos 31 al 35 mejora la capacidad de chaperona de la HspB6 (Figura 2 C). Esta región está muy conservada en las otras sHSP (Heirbaut et al., 2014).

\section{SPY}

La proteína Spy es una chaperona de 16 a $18 \mathrm{kDa}$ que pertenece a la familia $\mathrm{Cpx} / \mathrm{Spy}$, presente en protobacterias, endobacterias y en algunas cianobacterias (Koldewey, Horowitz \& Bardwell, 2017; Kwon, Kim, Gross, Gross \& Kim, 2010). Es una chaperona dimérica y su dimerización es necesaria para poder interaccionar con las proteínas sustrato (He, Sharpe, Mazur \& Hiller, 2016). No se ha observado que forme oligómeros en solución.

Spy es una proteína periplásmica y su expresión se regula por los sistemas de dos componentes Bae y $C p x$, que monitorean el plegamiento de las proteínas extra-citoplásmicas (Srivastava, Lambadi, Ghosh, Pathania \& Navani, 2014). La expresión de Spy aumenta con la exposición a diferentes tipos de estrés, principalmente el estrés osmótico y por la exposición a agentes que alteran la membrana, como el etanol y los antimicrobianos, y también durante la formación de esferoplastos (Vogt \& Raivio, 2012).

Spy tiene la función de evitar la agregación de las proteínas periplásmicas. Debido a la naturaleza permeable de la membrana externa muchas proteínas del periplasma se pueden desnaturalizar (Merdanovic, Clausen, Kaiser, Huber \& Ehrmann, 2004). La actividad de chaperona de Spy también favorece el plegamiento de las proteínas desplegadas, lo cual es importante debido a la ausencia de chaperonas dependientes del ATP en el periplasma (Koldewey, Stull, Horowitz, Martin \& Bardwell, 2016).
La proteína Spy de Escherichia coli tiene 161 residuos. La estructura del monómero consiste en cuatro $\alpha$-hélices que se estructuran formando una horquilla larga y curvada (Figura 2 D). La estructura se divide en tres regiones. Dos de ellas con un alto grado de desorden: la región 1 o N-terminal, que va de los residuos 1 al 52 (hélice 1, H1), y la región 3 o C-terminal, que va del residuo 144 al 161 (hélice 4, H4); en cambio, la región 2, que va de los residuos 53 al 143 está más estructurada y compuesta por las hélices 2 y 3 (H2 y H3) (Kwon et al., 2010). Las hélices H1 y $\mathrm{H} 2$ con la hélice más larga $\mathrm{H} 3$ forman dos puntas que están conectadas a través de un asa entre $\mathrm{H} 2$ y H3. La formación del dímero se da por la interacción del asa y una región cercana (H2 y el N-terminal de H3) de un monómero con las hélices H3 con H4 del C-terminal de otro monómero, de manera antiparalela. El dímero de Spy tiene una forma ovalada bastante plana y cóncava, parecida a una silla de montar (Figura 2 E). En la región cóncava es donde interaccionan las proteínas sustrato. Esta región tiene cuatro zonas hidrofóbicas rodeadas de aminoácidos hidrofílicos con carga positiva, pertenecientes a la región $\mathrm{N}$-terminal flexible y al asa que conecta $\mathrm{H} 1$ con $\mathrm{H} 2$ (Koldewey et al., 2017; Kwon et al., 2010; Wu, Stull, Lee \& Bardwell, 2019) (Figura 2 F).

La proteína Spy ha sido muy estudiada y sirve como modelo de la interacción chaperona/proteína sustrato. Esto se debe al tamaño pequeño de Spy y a que se han identificado algunos de sus sustratos específicos, como la proteína $\operatorname{Im} 7$ (Wu et al., 2019). El mecanismo por el que Spy favorece el plegamiento de otras proteínas se debe a que la proteína sustrato se une a la chaperona a partir de interacciones electrostáticas transitorias de largo alcance. Este complejo se estabiliza mediante interacciones hidrofóbicas de corto alcance, generando el colapso hidrofóbico de la proteína desplegada debido al desplazamiento de las moléculas de agua. Cuando se ocultan los residuos hidrofóbicos de la proteína sustrato la afinidad por Spy disminuye, permitiendo así su liberación (He et al., 2016; Hiller \& Burmann, 2018).

\section{HsP33}

Las Hsp33 son proteínas que van de los 25 a los $33 \mathrm{kDa}$ y pertenecen a la familia Hsp33. Están presentes en la mayoría de los procariontes así como en algunos parásitos eucariontes unicelulares, como los Tripanosomátidos, y también en algunas algas; no se encuentran en animales (Kumsta \& Jakob, 2009; Segal \& Shapira, 2015). La Hsp33 está normalmente como monómero en solución y es necesario la formación del dímero para su activación; la forma monomérica presenta una actividad de chaperona muy reducida (Chi et al., 2011; Graumann et al., 2001). El dímero en estado oxidado activo puede formar especies oligoméricas con mayor actividad que la especie dimérica (un $85 \%$ más eficiente) debido a un aumento significativo en las superficies hidrofóbicas expuestas en las especies oligoméricas, lo cual es relevante durante el estrés oxidante en la célula (Akhtar et al., 2004). 

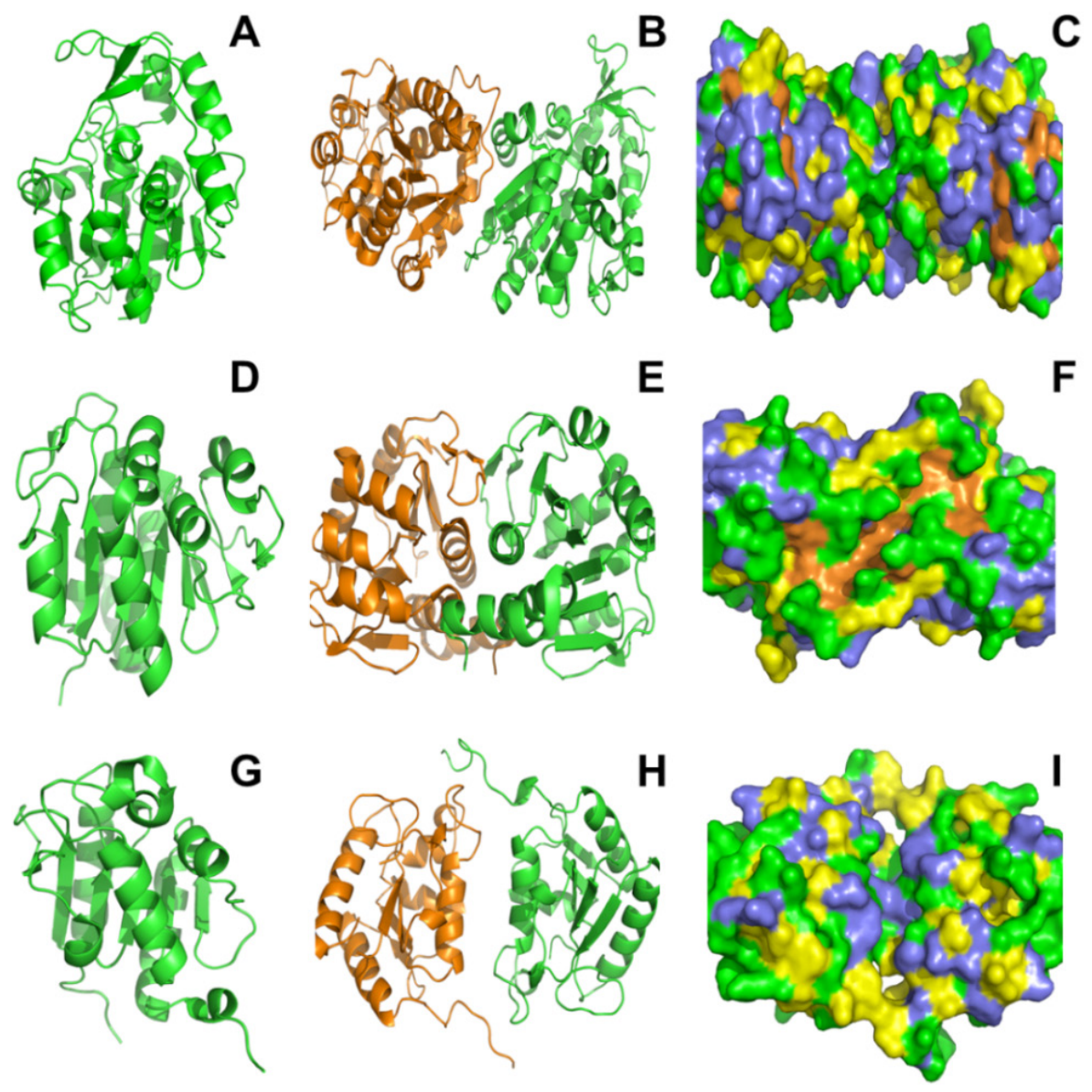

Figura 3. Estructuras cristalográficas de algunas chaperonas de la superfamilia DJ-1/ThiJ/PfpI. Estructuras de la Hsp31 de E. coli. A) Monómero. B) Dímero. C) Superficie del dímero. Estructuras de la DJ-1 de humano. D) Monómero. E) Dímero. F) Superficie del dímero. Estructuras del dominio C-terminal de la CAT-3 de $N$. crassa. G) Monómero. H) Dímero. I) Superficie del dímero. Los aminoácidos están marcados según lo indicado en la Figura 1. El arreglo de la forma dimérica puede ser empleada para clasificar las chaperonas de esta superfamilia: las que se ensamblan como la Hsp31 y las que lo hacen como la DJ-1(Wei, Ringe, Wilson \& Ondrechen, 2007). Hsp31 de E. coli puede generar especies oligoméricas cuando se une el zinc y también con una temperatura mayor a $60^{\circ} \mathrm{C}$, formando especies de alto peso molecular (Kim et al., 2018), sin embargo no hay estructura cristalográfica. Código de acceso del PDB: 1izy para los paneles A, B y C (Lee et al., 2003); 1ucf para los paneles D, E y F (Honbou et al., 2003); 3ej6 para los paneles G, H e I (Díaz, Valdés, Rudiño-Piñera, Horjales \& Hansberg, 2009).

La Hsp33 se localiza principalmente en el citoplasma donde evita la agregación de proteínas causada por la oxidación o por una temperatura elevada. Por otro lado, en las algas se localiza en los cloroplastos y es inducida cuando hay fotooxidación (Kumsta \& Jakob, 2009; Segal \& Shapira, 2015). En bacterias su expresión es constitutiva $(\sim 1.5 \mu \mathrm{M}$ en Escherichia coli) en ausencia de estrés y aumenta con diferentes tipos de estrés, como el oxidante, el calórico o el causado con el HOCl. En estas condiciones el factor de transcripción $\sigma^{32}$ determina su expresión y el factor transcripción OxyR la aumenta aún más con el estrés oxidante (Kumsta \& Jakob, 2009; Voth \& Jakob, 2017).

La Hsp33 de E. coli está compuesta por 294 aminoácidos y consta de dos dominios característicos de su estructura, el dominio de unión al sustrato o N-terminal que va del residuo 1 al 178 y el dominio donde se une el zinc o C-terminal que va del residuo 232 al 294; los dominios están conectados a través de una región de enlace que va del residuo 179 al 231 (Chi et al., 2011; Won et al., 2004) (Figura 2 G, H). La estructura del dominio donde se une el zinc consta de dos hélices que forman un ángulo recto entre sí, además de tener una horquilla de hojas $\beta$ plegadas y una tercera hélice en el extremo carboxilo. Este dominio presenta un motivo conservado de cuatro cisteínas $\mathrm{C}-\mathrm{X}-\mathrm{C}-\mathrm{X}_{\mathrm{n}}-\mathrm{C}-\mathrm{X}-\mathrm{X}-\mathrm{C}(232,234,262$ y 265 en E. coli) que incorporan un ion de zinc (Reichmann et al., 2012; Won et al., 2004). En las algas, la Hsp33 perdió la primera cisteína del motivo. Aunque presenta actividad de chaperona y el zinc se sigue uniendo, su capacidad para reconocer los 
sustratos está disminuida en comparación con las Hsp33 de las bacterias (Segal \& Shapira, 2015). La estructura del dominio que incorpora el zinc tiene un mecanismo de activación que funciona como un interruptor redox: la pérdida del ión de zinc altera la estructura plegada de la proteína, permitiendo que las cisteínas se oxiden formando puentes disulfuro. Esta oxidación provoca la desestructuración de la región de enlace ( 40 aminoácidos) que en condiciones normales está plegada, es estable e interacciona con la superficie hidrófoba del dominio N-terminal (Cremers, Reichmann, Hausmann, Ilbert \& Jacob, 2010; Groitl et al., 2016; Won et al., 2004). Para su activación es necesaria la presencia simultánea de agentes oxidantes, como el $\mathrm{H}_{2} \mathrm{O}_{2}$, y de una temperatura elevada $\left(>40^{\circ} \mathrm{C}\right)$ (Graumann et al., 2001).

La Hsp33 interacciona con las proteínas desplegadas mediante la desestructuración de la región de enlace, lo que la vuelve más flexible y expone los residuos hidrofóbicos esenciales para su interacción con las proteínas sustrato, los cuales están rodeados de residuos polares que participan en la interacción. La zona de interacción más fuerte con las proteínas sustrato involucra a los aminoácidos F157, M172, F187, L202, L203, W212 y Y223, mientras que los aminoácidos Y12 y Y39 del dominio $\mathrm{N}$-terminal presentan un menor número de interacciones (Figura 2 I). El dominio C-terminal no está implicado en la unión con las proteínas sustrato (Groitl et al., 2016). La Hsp33 ha sido estudiada como modelo debido a que su función de chaperona se da mediante la interacción entre una región desestructurada de la chaperona con las proteínas sustrato desdobladas.

\section{HsP31}

Las Hsp31 son proteínas que van de los 25 a los $33 \mathrm{kDa}$. Pertenecen a la superfamilia de proteínas DJ-1/ThiJ/PfpI que están presentes en los tres dominios de la vida, siendo la proteína DJ-1 humana la más estudiada (Aslam \& Hazbun, 2016; Lucas \& Marín, 2007). Los miembros de la familia DJ-1 con actividad de chaperona se caracterizan por ser proteínas diméricas y se pueden clasificar según la forma en la que se unen los monómeros en el dímero (Jung et al., 2012; Wei, Ringe, Wilson \& Ondrechen, 2007). Algunos miembros de esta superfamilia se organizan en hexámeros cuya unidad principal son dímeros, como el caso de la proteasa PfpI en bacterias, pero no se ha observado que estas proteínas tengan actividad de chaperona (Jung et al., 2012). Las proteínas mutantes de DJ-1 humana que inhiben la formación del dímero carecen de actividad de chaperona y se degradan (Alvarez-Castelao, Sánchez, Goethals, Vandekerckhove \& Castaño, 2012; Blackinton et al., 2005). Hsp31 en E. coli se oligomeriza cuando incorpora un ión de zinc y también con una temperatura mayor a $60^{\circ} \mathrm{C}$, formando especies de alto peso molecular, lo que incrementa significativamente su actividad de chaperona debido al aumento de la zona hidrofóbica expuesta en la superficie del oligómero (Kim et al., 2018).
Las proteínas Hsp31 se localizan principalmente en el citoplasma en condiciones normales, tanto en procariontes como en eucariontes, aunque durante condiciones de estrés también se localizan en los cuerpos $\mathrm{P}$ y en los cuerpos de inclusión (Aslam \& Hazbun, 2016; Bankapalli et al., 2015). La Hsp31 en las levaduras se transloca del citoplasma a las mitocondrias durante condiciones de estrés, principalmente estrés oxidante, y contribuye a preservar la integridad mitocondrial manteniendo el NADPH y por ende el glutatión (Aslam \& Hazbun, 2016; Bankapalli et al., 2015). En humanos, DJ-1 no sólo se localiza en el citoplasma, la mitocondria y los cuerpos de estrés, sino también en el núcleo, en el aparato de Golgi, en el retículo endoplásmico y en las balsas lipídicas de la membrana celular (Kim et al., 2013; Kim et al., 2012; Moutaoufik et al., 2019; Usami et al., 2011).

Aunque en el humano DJ-1 se ha asociado con múltiples funciones (glioxalasa/deglicasa, peptidasa, cofactor transcripcional, oxidoreductasa tipo peroxirredoxina, atrapador de cobre, proteínas de unión a hormonas), aún no está clara su actividad principal en las células. Sin embargo, la actividad de chaperona es importante, ya que en el caso de las mutaciones de DJ-1 que tienen disminuida esta función, aumenta la agregación de proteínas en las células del cerebro, como la $\alpha$-sinucleina, asociada con diferentes enfermedades neurodegenerativas como el Parkinson y el Alzheimer (Alvarez-Castelao et al., 2012; Dolgacheva, Berezhnov, Fedotova, Zinchenko \& Abramov, 2019). La Hsp31 de E. coli y las de Saccharomyces cerevisiae tienen actividad de desglicasa (glioxalasa) y de chaperona (Aslam \& Hazbun, 2016; Bankapalli etal., 2015). Además, en el caso de la Hsp31 de E. coli se ha observado in vitro que puede ayudar a la recuperación de la forma nativa de las proteínas después de ser desnaturalizadas (Sastry Korotkov, Brodsky \& Baneyx, 2002). Las diferentes Hsp31 de S. cerevisiae protegen a la célula de la agregación de proteínas y desagregan las fibrillas que se producen durante el estrés oxidante, el osmótico o una temperatura elevada, y también evitan la agregación de la proteína prion Sup35. Además, evaden la toxicidad celular debida a la modificación de las proteínas por el metilglioxal, el glioxal o el ácido acético, producidos en la glicólisis. Se ha visto que están implicadas en la supervivencia de las levaduras durante el crecimiento diaúxico y la fase de crecimiento estacionario (Miller-Fleming et al., 2014; Skoneczna, Kaniak \& Skoneczny, 2015; Tsai et al., 2015). En E. coli la Hsp31 protege a la célula de la toxicidad debido a la agregación de proteínas de manera independiente de otros sistemas de chaperonas, e incrementa la supervivencia de las bacterias cuando el $\mathrm{pH}$ del medio se acidifica en la fase estacionaria (Malki, Kern,Abdallah \& Richarme, 2003; Mujacic, Bader \& Baaneyx, 2004; Mujacic \& Baneyx, 2006).

La Hsp31 de E. coli consta de 286 aminoácidos y tiene dos dominios característicos en su estructura, el dominio A y el dominio $\mathrm{P}$, que están unidos por un asa de enlace flexible 
(Figura 3 A). El dominio A, también llamado dominio ThiJ, tiene una estructura tipo Rossmann que está compuesta por un arreglo de $\alpha$-hélices y hojas $\beta$ antiparalelas. En este arreglo las $\alpha$-hélices rodean las hojas $\beta$ en forma de sandwich. En el dominio A se encuentra la triada catalítica Cys-His-Glu(Asp) característica de la superfamilia DJ-1/ThiJ/PfpI; mientras que el dominio $\mathrm{P}$ es responsable de la dimerización. El dímero presenta una forma cóncava tipo cuenco en donde hay varios aminoácidos hidrofóbicos rodeados de aminoácidos con carga, los cuales interaccionan con las proteínas sustrato (Lee et al., 2003; Quigley, Korotkov, Baneyx \& Hol, 2003, 2004) (Figura 3 B).

La zona de interacción con las proteínas sustrato no ha sido identificada completamente, pero para la Hsp31 de E. coli se ha observado una reducción de la actividad de chaperona al mutar algunos aminoácidos hidrofóbicos de la zona del cuenco del dominio A y del asa de enlace. En el dominio A las mutaciones F19E, F20E y Y24E reducen la actividad en un 20\% mientras que la mutación L26E la reduce en un 50-60\%. Por otro lado, las sustituciones L80E y I220E en el asa reducen la actividad en un $60-65 \%$, mientras que L85E la reduce en un 35\% (Figura $3 \mathrm{C})$. Esto sugiere que la interacción con la proteína sustrato ocurre en la superficie hidrofóbica del cuenco y que la actividad es regulada por el asa de enlace, que normalmente cubre esta zona y con una temperatura elevada $\left(>45^{\circ} \mathrm{C}\right)$ se produce un cambio conformacional que flexibiliza el asa y expone la región hidrofóbica (Quigley, Korotkov, Baneyx \& Hol, 2004; Sastry, Quigley, Hol \& Baneyx, 2004) (Figura 3 C). En el caso de la DJ-1 humana se considera como posible zona de interacción una región hidrofóbica extensa en la superficie de la proteína comprendida por los aminoácidos V146, F162, L166, A167, A178 y L187 (Lee et al., 2003) (Figura 3 D-F).

Las catalasas de subunidad grande (large subunit catalases, LSC) son proteínas presentes en bacterias, hongos y algunas arqueas. A diferencia de otras hemo-catalasas tienen un dominio extra en el extremo carboxilo de entre 100 y 190 aminoácidos (Díaz, Valdés, Rudiño-Piñera, Horjales \& Hansberg, 2009; Hansberg, Salas-Lizana \& Domínguez, 2012). Este dominio C-terminal se ha incluido en la superfamilia DJ-1/ThiJ/PfpI debido a su parecido estructural con estas proteínas, aunque a nivel de secuencia no se parecen y tampoco conservan la triada catalítica característica de la superfamilia (Hansberg, Salas-Lizana \& Domínguez, 2012; Lucas \& Marín, 2007) (Figura 3 G-I). Se ha observado que el dominio C-terminal le confiere estabilidad a las catalasas en condiciones de estrés calórico (Chelikani, Donald, Duckworth \& Loewen, 2003). Hemos descubierto que este dominio C-terminal también presenta actividad de chaperona molecular en condiciones in vitro protegiendo a otras proteínas de la desnaturalización debida a una temperatura elevada, a una concentración alta de urea o a la oxidación con $\mathrm{H}_{2} \mathrm{O}_{2}$ y es más eficiente como chaperona que la Hsp31 de E. coli (Nava Ramírez, 2017). El C-terminal aislado de la catalasa-3 de $N$. crassa confiere a $E$. coli una mayor supervivencia en condiciones de estrés calórico y oxidante (Nava Ramírez \& Hansberg, 2020). Algunos datos preliminares indican que varios aminoácidos hidrofóbicos de la superficie del dominio son importantes para su función de chaperona.

\section{PaRTICIPACIÓN de ZONAS HIDROFóbICAS Y AMINO- ÁCIDOS CARGADOS}

En todos los casos las zonas de interacción con el sustrato presentan principalmente aminoácidos hidrofóbicos así como algunos aminoácidos con carga que pueden interactuar con la proteína sustrato. En el caso de Spy, el plegamiento de la proteína sustrato depende del desplazamiento de las moléculas de agua desde el interior de la proteína debido a las interacciones hidrofóbicas y a la desestructuración de los aminoácidos de una región mal plegada mediante las interacciones electrostáticas, lo que favorece el plegamiento de la proteína sustrato en su estructura nativa funcional (He et al., 2016; Hiller \& Burmann, 2018).

\section{LA IMPORTANCIA DE LA ESTRUCTURA DIMÉRICA}

En los ejemplos mencionados en esta revisión, la dimerización de las chaperonas es necesaria y en algunos casos, como los de Spy, Hsp33 y Hsp31, es esencial para su actividad. La forma monomérica de este tipo de chaperonas no presenta actividad o es muy reducida. La formación del dímero en las sHSP, Hsp31 y Spy favorece los sitios de unión con la proteína sustrato al aumentar la superficie hidrofóbica, además en Hsp31 y Spy también se favorece la formación de una estructura cóncava que es importante para la interacción con la proteína sustrato (Dreiza et al., 2010; Koldewey et al., 2017; Liu et al., 2018; Sastry et al., 2004). En el caso de la Hsp33 la formación del dímero permite la activación por oxidación de la chaperona, esto genera la desorganización de una parte de la proteína y una mayor exposición de la zona hidrofóbica, lo que favorece la interacción con las proteínas sustrato (Groitl et al., 2016).

\section{LA OLIGOMERIZACIÓN CONTROLA LA ACTIVIDAD DE CHAPERONA}

En los casos de las chaperonas que pueden generar oligómeros el cambio estructural es importante para la regulación de la actividad de chaperona, ya sea de manera negativa o positiva. En la $\alpha \mathrm{B}$-cristalina la formación de oligómeros de alto peso molecular regula negativamente su actividad, ya que involucra el surco hidrofóbico formado por las cadenas $\beta 4 / \beta 8$ que es la zona de interacción con las proteínas sustrato. En condiciones de estrés se deshacen los oligómeros y con la exposición del surco hidrofóbico se incrementa la actividad de chaperona (Groitl et al., 2016; Liu et al., 2018). En la Hsp31 y la Hsp33 la formación de oligómeros regula de manera positiva su actividad, ya que aumenta la exposición de las zonas hidrofóbicas. En ambos casos se requieren condiciones de estrés para la oligomerización (Akhtar et al., 2004; Kim et al., 2018). En el caso de la Hsp20 (HspB6), aunque no puede 
formar homo-oligómeros, la formación de hetero-oligoméros regula su actividad de dos formas dependiendo con cuál de las sHSP interacciona: al unirse con HspB1 se vuelve más específica a un tipo de sustrato y al unirse a HSpB5 aumenta su actividad de chaperona en comparación con las especies de homo-oligómeros más grandes de HspB5 (Mymrikov et al., 2019). Esto también ocurre en las chaperonas dependientes del ATP, las cuales forman complejos que potencian su actividad, como es el caso del complejo Hsp40/Hsp70 o las Hsp60 (GroEL en bacterias y TRiC en eucariontes) que se organizan en maquinarias moleculares sumamente complejas (Hartl et al., 2011). Estos datos sugieren que la estructura oligomérica de una chaperona es un aspecto relevante y posiblemente sea un factor determinante para su actividad.

\section{Agradecimientos}

Se agradece el apoyo en la revisión y los consejos oportunos a Sammy Israel Gutiérrez Terrazas. Teresa Nava Ramírez es alumna de doctorado del Programa de Maestría y Doctorado en Ciencias Bioquímicas, Universidad Nacional Autónoma de México (UNAM) y recibió la beca 480865, CVU501149 del Consejo Nacional de Ciencia y Tecnología. Los proyectos del laboratorio del Dr. Hansberg se han apoyado con recursos del PAPIIT (UNAM), proyecto IN208717.

\section{REFERENCIAS}

Akhtar, M. W., Srinivas, V., Raman, B., Ramakrishna, T., Inobe, T., Maki, K., Arai, M., Kuwajima, K. \& Rao, C. M. (2004). Oligomeric Hsp33 with enhanced chaperone activity: gel filtration, cross-linking, and small angle x-ray scattering (SAXS) analysis. Journal of Biological Chemistry, 279(53), 55760-55769. DOI: 10.1074/jbc.M406333200

Alvarez-Castelao, B., Muñoz, C., Sánchez, I., Goethals, M., Vandekerckhove, J. \& Castaño, J. G. (2012). Reduced protein stability of human DJ-1/PARK7 L166P, linked to autosomal recessive Parkinson disease, is due to direct endoproteolytic cleavage by the proteasome. Biochimica et Biophysica Acta, 1823(2), 524-533. DOI: 10.1016/j. bbamcr.2011.11.010

Aslam, K. \& Hazbun, T. R. (2016). Hsp31, a member of the DJ-1 superfamily, is a multitasking stress responder with chaperone activity. Prion, 10(2), 103-111. DOI: 10.1080/19336896.2016.1141858

Bagnéris, C., Bateman, O., Naylor, C., Cronin, N., Boelens, W., Keep, N. \& Slingsby, C. (2009). Crystal structures of a-crystallin domain dimers of aB-crystallin and Hsp20. Journal of Molecular Biology, 394(3), 1242-1252. DOI: 10.1016/j.jmb.2009.09.060

Bankapalli, K., Saladi, S., Awadia, S. S., Goswami, A. V., Samaddar, M. \& D'Silva, P. (2015). Robust glyoxalase activity ofHsp31, a ThiJ/DJ-1/PfpI family member protein, is critical for oxidative stress resistance in Saccharomyces cerevisiae. Journal of Biological Chemistry, 290(44), 26491-26507. DOI: 10.1074/jbc.M115.673624
Blackinton, J., Ahmad, R., Miller, D. W., van der Brug, M. P., Canet-Avilés, R. M., Hague, S. M., Kaleem, M. \& Cookson, M. R. (2005). Effects of DJ-1 mutations and polymorphisms on protein stability and subcellular localization. Molecular Brain Research, 134(1), 76-83. DOI: 10.1016/j.molbrainres.2004.09.004

Boelens, W. (2014). Cell biological roles of aB-crystallin. Progress in Biophysics and Molecular Biology, 115(1), 3-10. DOI: 10.1016/j.pbiomolbio.2014.02.005

Braun, N., Zacharias, M., Peschek, J., Kastenmueller, A., Zou, J., Hanzlik, M., Haslbeck, M., Rappsilber, J., Buchner, J. \& Weinkauf, S. (2011). Multiple molecular architectures of the eye lens chaperone alpha beta-crystallin elucidated by a triple hybrid approach. Proceedings of the National Academia of Sciences of the United Estates of America, 108(51), 20491-20496. DOI: 10.1073/pnas.1111014108

Brodehl, A., Gaertner-Rommel, A., Klauke, B., Grewe, S. A., Schirmer, I., Peterschröder, A., Faber, L., Vorgerd, M., Gummert, J., Anselmetti, D., Schulz, U., Paluszkiewicz, L. \& Milting, H. (2017). The novel aB-crystallin (CRYAB) mutation p.D109G causes restrictive cardiomyopathy. Human Mutation, 38(8), 947-952. DOI: 10.1002/ humu. 23248

Bukach, O. V., Seit-Nebi, A. S., Marston, S. B. \& Gusev, N. B. (2004). Some properties of human small heat shock protein Hsp20(HspB6). European Journal of Biochemistry, 271(2), 291-302. DOI: 10.1046/j.1432-1033.2003.03928.x

Chelikani, P., Donald, L. J., Duckworth, H. W. \& Loewen, P. C. (2003). Hydroperoxidase II of Escherichia coli exhibits enhanced resistance to proteolytic cleavage compared to other catalases. Biochemistry, 42(19), 5729-5735. DOI: 10.1021/bi034208j

Chi, S. W., Jeong, D. G., Woo, J. R., Lee, H. S., Park, B. C., Kim., B. Y., Erikson, R. L., Ryu, S. E. \& Kim, S. J. (2011). Crystal structure of constitutively monomeric E. coli Hsp33 mutant with chaperone activity. FEBSLetters, 585(4), 664 670. DOI: 10.1016/j.febslet.2011.01.029

Cremers, C. M., Reichmann, D., Hausmann, J., Ilbert, M. \& Jacob, U. (2010). Unfolding of metastable linker region is at the core ofHsp33 activation as a redox-regulated chaperone. Journal of Biological Chemistry, 285(15), 11243-11251. DOI: 10.1074/jbc.M109.084350

den Engelsman, J., Bennink, E., Doerwald, L., Onnekink, C., Wunderink, L., Andley, U. P., Kato, K., de Jong, W. W. \& Boeleens, W. C. (2004). Mimicking phosphorylation of the small heat-shock protein aB-crystallin recruits the F-box protein FBX4 to nuclear SC35 speckles. European Journal ofBiochemistry, 271(21), 4195-4203. DOI: 10.1111/j.14321033.2004.04359.x

Díaz, A., Valdés, V. J., Rudiño-Piñera, E., Horjales, E. \& Hansberg, W. (2009). Structure-function relationships in fungal large-subunit catalases. Journal of Molecular Biology, 386(1), 218-232. DOI: 10.1016/j. jmb.2008.12.019 
Dimauro, I., Antonioni, A., Mercatelli, N. \& Caporossi, D. (2017). The role of aB-crystallin in skeletal and cardiac muscle tissues. Cell Stress and Chaperones, 23(4), 491-505. DOI: $10.1007 / \mathrm{s} 12192-017-0866-\mathrm{x}$

Dolgacheva, L. P., Berezhnov, A. V., Fedotova, E. I., Zinchenko, V. P. \& Abramov, A. Y. (2019). Role of DJ-1 in the mechanism of pathogenesis of Parkinson's disease. Journal of Bioenergetics and Biomembranes, 51(3), 175-188. DOI: 10.1007/s10863-019-09798-4

Dreiza, C. M., Komalavilas, P., Furnish, E. J., Flynn, C. R., Sheller, M., Smoke, C. C., Lopes, L. B. \& Brophy, C. M. (2010). The small heat shock protein, HSPB6, in muscle function and disease. Cell Stress and Chaperones, 15(1), 1-11. DOI: 10.1007/s12192-009-0127-8

Edwards, H. V., Cameron, R. T. \& Baillie, G. S. (2011). The emerging role of HSP20 as a multifunctional protective agent. Cell Signalling, 23(9), 1447-1454. DOI: 10.1016/j. cellsig.2011.05.009

Fan, G. C. \& Kranias, E. (2010). Small heat shock protein 20 (HspB6) in cardiac hypertrophy and failure. Journal of Molecular and Cellular Cardiology, 51(4), 574-577. DOI: 10.1016/j.yjmcc.2010.09.013

Fuchs, M., Poirier, D. J., Seguin, S. J., Lambert, H., Carra, S., Charette, S. J. \& Landry, J. (2009). Identification of the key structural motifs involved in HspB8/HspB6-Bag3 interaction. Biochemical Journal, 425(1), 245-255. DOI: 10.1042/BJ20090907

Golenhofen, N., Perng, M. D., Quinlan, R.A.\& Drenckhahn, D. (2004). Comparison of small heat shock proteins alphaBcrystallin, MKBP, $\mathrm{HSP}_{25}, \mathrm{HSP}_{20}$, cvHSP in heart and skeletal muscle. Histochemistry and Cell Biology, 122(5), 415-425. DOI: $10.1007 / \mathrm{s} 00418-004-0711-\mathrm{z}$

Graumann, J., Lilie, H., Tang, X., Tucker, K. A., Hoffmann, J. H., Vijayalakshmi, J., Saper, M., Bardwell, J. C. \& Jakob, U. (2001). Activation of the redox-regulated molecular chaperone Hsp33 - A two-step mechanism. Structure, 9(5), 377-387. DOI: 10.1016/s0969-2126(01)00599-8

Groitl, B., Horowitz, S., Makepeace, K. A. T., Petrotchenko, E. V., Borchers, C. H., Reichmann, D., Bardwell, J. C. A. \& Jacob, U. (2016). Protein unfolding as a switch from self-recognition to high-affinity client binding. Nature Communications, 7(1), 1-12. DOI: 10.1038/ ncomms 10357

Gruvberger-Saal, S. \& Parsons, R. (2006). Is the small heat shock protein aB-crystallin an oncogene? The Journal of Clinical Investigation, 116(1), 30-32. DOI: 10.1172/JCI27462

Hall, D. (2019). On the nature of the optimal form of the holdase-type chaperone stress response. FEBS Letters, 594(1), 43-66. DOI: 10.1002/1873-3468.13580

Hansberg, W., Salas-Lizana, R. \& Domínguez, L. (2012). Fungal catalases: function, phylogenetic origin and structure. Archives of Biochemistry and Biophysics, 525(2), 170-180. DOI: 10.1016/j.abb.2012.05.014

Hartl, F. U., Bracher, A. \& Hayer-Hartl, M. (2011). Molecular chaperones in protein folding and proteostasis. Nature, 575(7356), 324-332. DOI: 10.1038/nature10317

Hartl, F. U. \& Hayer-Hartl, M. (2009). Converging concepts of protein folding in vitro and in vivo. Nature Structural and Molecular Biology, 16(6), 574-581. DOI: 10.1038/ nsmb.1591

He, L., Sharpe, T., Mazur, A. \& Hiller, S. (2016). A molecular mechanism of chaperone-client recognition. Science Advances, 2(11), e1601625-e1601629. DOI: 10.1126/ sciadv. 1601625

Heirbaut, M., Beelen, S., Strelkov, S. V. \& Weeks, S. D. (2014). Dissecting the functional role of the N-terminal domain of the human small heat shock protein HSPB6. PLoSOne, 9(8), e105892- e105892. DOI: 10.1371/journal.pone.0105892

Hiller, S.\&Burmann,B.M.(2018). Chaperone-clientcomplexes: a dynamic liaison. Journal of Magnetic Resonance, 289(1), 142-155. DOI: 10.1016/j.jmr.2017.12.008

Honbou, K., Suzuki, N. N., Horiuchi, M., Niki, T., Taira, T., Ariga, H. \& Inagaki, F. (2003). The Crystal structure ofDJ-1, a protein related to male fertility and Parkinson's disease. Journal of Biological Chemistry, 278(33), 31380-31384. DOI: 10.1074/jbc.M305878200

Janda, I., Devedjiev, Y., Derewenda, U., Dauter, Z., Bielnicki, J., Cooper, D. R., Graf, P. C., Joachimiak, A., Jakob, U. \& Derewenda, Z. S. (2004). The crystal structure of the reduced, $\mathrm{Zn}^{2+}$-bound form of the $B$. subtilis Hsp33 chaperone and its implications for the activation mechanism. Structure, 12(10), 1901-1907. DOI: 10.1016/j.str.2004.08.003

Jaspard, E. \& Hunault, G. (2016). sHSPdb: A database for the analysis of small Heat Shock Proteins. BCM Plant Biology, 16(1), 135-146. DOI: 10.1186/s12870-016-0820-6

Jin, J., Whittaker, R., Glassy, M., Barlow, S., Gottlieb, R. \& Glembotski, C. (2008). Localization of phosphorylated aB-crystallin to heart mitochondria during ischemiareperfusion. American Journal of Physiology-Heart and Circulatory Physiology, 294(1), H337-H344. DOI: 10.1152/ajpheart.00881.200

Jung, H. J., Kim, S., Kim, Y. J., Kim, M-K., Kang, S. G., Lee, J-H., Kim, W. \& Cha, S-S. (2012). Dissection of the dimerization modes in the DJ-1 superfamily. Molecules and Cells, 33(2), 163-171. DOI: 10.1007/s10059-012-2220-6

Kim, J., Choi, D., Cha, S. Y., Oh, Y. M., Hwang, E., Park, C. \& Ryu, K.S. (2018).Zinc-mediated reversible multimerization of Hsp31 enhances the activity of holding chaperone. Journal of Molecular Biology, 430(12), 1760-1772. DOI: 10.1016/j.jmb.2018.04.029

Kim, K. S., Kim, J. S., Park, J-Y., Suh, Y. H., Jou, I., Joe, E. H. \& Park, S. M. (2013). DJ-1 associates with lipid rafts by palmitoylation and regulates lipid rafts-dependent endocytosis in astrocytes. Human Molecular Genetics, 22(23), 4805-4817. DOI: 10.1093/hmg/ddt332

Kim, S-J., Park, Y-J., Hwang, I-Y., Youdim, M. B. H., Park, K. S. \& Oh, Y. J. (2012). Nuclear translocation of DJ-1 during oxidative stress-induced neuronal cell death. Free Radical 
Biology \& Medicine, 53(4), 936-950. DOI: 10.1016/j. freeradbiomed.2012.05.035

Klemenz, R., Andres, A., Fröhli, E., Schäfer, R. \& Aoyama, A. (1993). Expression of the murine small heat shock proteins $\mathrm{HSP}_{25}$ and alpha $\mathrm{B}$ crystallin in the absence of stress. Journal of Cell Biology, 120(3), 639-645. DOI: 10.1083/jcb.120.3.639

Koldewey, P., Horowitz, S. \& Bardwell, J. (2017). Chaperone-client interactions: Non-specificity engenders multifunctionality. Journal of Biological Chemistry, 292(29), 12010-12017. DOI: 10.1074/jbc.R117.796862

Koldewey, P., Stull, F., Horowitz, S., Martin, R. \& Bardwell, J. (2016). Forces driving chaperone action. Cell, 166(2), 369-379. DOI: 10.1016/j.cell.2016.05.054

Kriegenburg, F., Jakopec, V., Poulsen, E. G., Nielsen, S. V., Roguev, A., Krogan, N., Gordon, C., Fleig, U. \& HartmannPetersen, R. (2014). A chaperone-assisted degradation pathway targets kinetochore proteins to ensure genome stability. PLoS Genetics, 10(1), e1004140-e1004140.DOI: 10.1371/journal.pgen.1004140

Kumsta, C. \& Jakob, U. (2009). Redox-regulated chaperones. Biochemistry, 48(22), 4666-4676. DOI: 10.1021/bi9003556

Kwon, E., Kim, D. Y., Gross, C. A., Gross, J. D. \& Kim, K. K. (2010). The crystal structure Escherichia coli Spy. Protein Sciencies, 19(11), 2252-2259. DOI: 10.1002/pro.489

Lee, S-J., Kim, S. J., Kim, I-K., Ko, J., Jeong, C-S., Kim, G-H., Park, C., Kang, S-O., Suh, P-G., Lee, H-L. \& Cha, S-S. (2003). Crystal structures of human DJ-1 and Escherichia coli $\mathrm{Hsp} 31$ that share an evolutionarily conserved domain. Journal of Biological Chemistry, 278(45), 44552-44559. DOI: $10.1074 /$ jbc.M304517200

Li, F., Xiao, H., Zhou, F., Hu, Z. \& Yang, B. (2017). Study of HspB6: insights into the properties of multifunctional protective agent. Cell Physiology and Biochemistry, 44(1), 314-332. DOI: 10.1159/000484889

Liu, Z., Wang, C., Li, Y., Zhao, C., Li, T., Li, D., Zhang, S. $\&$ Liu, C. (2018). Mechanistic insights into the switch of aB-crystallin chaperone activity and self-multimerization. Journal of Biological Chemistry, 293(38), 14880-14890. DOI: $10.1074 /$ jbc.ra118.004034

Lucas, J. I. \& Marín, I. (2007). A new evolutionary paradigm for the Parkinson disease gene DJ-1. Molecular Biology and Evolution, 24(2), 551-556. DOI: 10.1093/molbev/ msl186

Macario, A., Conway de Macario, E. \& Cappello, F. (2013). Chaperones: general characteristics and classifications. In The Chaperonopathies pp. 15-33. SpringerBriefs in Biochemistry and Molecular Biology, Springer, Dordrecht. DOI: 10.1007/978-94-007-4667-1_2\%0A

Malki, A., Kern, R., Abdallah, J. \& Richarme, G. (2003). Characterization of the Escherichia coli YedU protein as a molecular chaperone. Biochemical and Biophysical Research Communications, 301(2), 430-436.DOI: 10.1016/ s0006-291x(02)03053-x
Merdanovic, M., Clausen, T., Kaiser, M., Huber, R. \& Ehrmann, M. (2004). Protein quality control in the bacterial periplasm. Annual Review of Microbiology, 65(1), 149-168. DOI: 10.1146/annurev-micro-090110-102925

Miller-Fleming, L., Antas, P., Pais, T. F., Smalley, J. L., Giorgini, F. \& Outeiro, T. F. (2014). Yeast DJ-1 superfamily members are required for diauxic-shift reprogramming and cell survival in stationary phase. Proceedings of the National Academia of Sciences of the United Estates of America, 111(19), 7012-7017. DOI: 10.1073/ pnas. 1319221111

Morimoto, R. (2002). Dynamic remodeling of transcription complexes by molecular chaperones. Cell, 110(3), P281284. DOI: $10.1016 / \mathrm{S} 0092-8674(02) 00860-7$

Moutaoufik, M. T., Malty, R, Amin S., Zhang Q., Phanse S., Gagarinova A., Zilocchi M., Hoell L., Minic Z., Gagarinova M.,Aoki H., Stockwell J., Jessulat M., Goebels F., Broderick K., Scott N. E., Vlasblom J., Musso G., Prasad B, Lamantea E., Garavaglia B., Rajput A., Murayama K., Okazaki Y., Foster L. J., Bader G. D., Cayabyab F. S. \& Babu M. (2019). Rewiring of the human mitochondrial interactome during neuronal reprogramming reveals regulators of the respirasome and neurogenesis. ISciences, 19(27), 1114-1132. DOI: 10.1016/j.isci.2019.08.057

Mujacic, M., Bader, M. W. \& Baneyx, F. (2004). Escherichia coli $\mathrm{Hsp} 31$ functions as a holding chaperone that cooperates with the DnaK-DnaJ-GrpE system in the management of protein misfolding under severe stress conditions. Molecular Microbiology, 51(3), 849- 859. DOI: 10.1046/j.13652958.2003.03871.x

Mujacic, M. \& Baneyx, F. (2006). Regulation of Escherichia coli hchA, a stress-inducible gene encoding molecular chaperone Hsp31. Molecular Microbiology, 60(6), 1576-1589. DOI: 10.1111/j.1365-2958.2006.05207.x

Muranova, L. \& Gusev, N. S. (2018). aB-crystallin phosphorylation: advances and problems. Biochemistry (Moscow), 83(10), 1196-1206. DOI: 10.1146/annurevmicro-090110-102925.

Mymrikov, E. V., Riedl, M., Peters, C., Weinkauf, S., Haslbeck, M. \& Buchner, J. (2019). Regulation of small heat shock proteins by hetero-oligomer formation. Journal of Biological Chemistry, 295(1), 158-169. DOI: 10.1074/jbc. RA119.011143

Nava Ramírez, T. (2017). Las catalasas de subunidad grande también son chaperonas. Tesis de Maestría, UNAM. 1-84

Nava Ramírez, T. \& Hansberg, W. (2020).Chaperone activity of large-size subunit catalases. Free Radical Biology \& Medicine, 156, 99-106. DOI: 10.1016/j. freeradbiomed.2020.05.020

Niwa, M., Kozawa, O., Matsuno, H., Kato, K. \& Uematsu, T. (2000). Small molecular weight heat shock-related protein, $\mathrm{HSP}_{20}$, exhibits an anti-platelet activity by inhibiting receptor-mediated calcium influx. Life Sciences, 66(1), PL7-12. DOI: 10.1016/s0024-3205(99)00566-4 
Quan, S., Koldewey, P., Tapley, T., Kirsch, N., Ruane, K. M., Pfizenmaier, J., Shi, R., Hofmann, S., Foit, L., Ren, G., Jakob, U., Xu, Z., C., Ygler, M. \& Bardwell, J. C. (2011). Genetic selection designed to stabilize proteins uncovers a chaperone called Spy. Nature Structural and Molecular Biology, 18(1), 262-269. DOI: 10.1038/nsmb.2016

Quigley, P. M., Korotkov, K., Baneyx, F. \& Hol, W. G. (2004). A new native EcHsp31 structure suggests a key role of structural flexibility for chaperone function. Protein Sciencies, 13(1), 269-277. DOI: 10.1110/ps.03399604

Quigley, P. M., Korotkov, K., Baneyx, F. \& Hol, W. G. J. (2003). The 1.6- $\AA$ crystal structure of the class of chaperones represented by Escherichia coli Hsp31 reveals a putative catalytic triad. Proceedings of the National Academia of Sciences of the United Estates of America, 100(6), 3137-3142. DOI: 10.1073/pnas.0530312100

Reichmann, D., Xu, Y., Cremers, C. M., Ilbert, M., Mittelman, R., Fitzgerald, M. C. \& Jakob, U. (2012). Order out of disorder: working cycle of an intrinsically unfolded chaperone. Cell, 148(5), 947-957. DOI: 10.1016/j.cell.2012.01.045

Rembold, C. M. \& Zhang, E. (2001). Localization of heat shock protein 20 in swine carotid artery. BCM Physiology, 1(20), 1-5. DOI: 10.1186/1472-6793-1-10

Saio, T., Kawagoe, S., Ishimori, K. \& Kalodimos, C. (2018). Oligomerization of a molecular chaperone modulates its activity. ELife, 7(e35731). 1-18. DOI: 10.7554/ eLife. 35731

Santhanagopalan, I., Degiacomi, M., Shepherd, D., Hochberg, G., Benesch, J. \& Vierling, E. (2018). It takes a dimer to tango: oligomeric small heat shock proteins dissociate to capture substrate. Journal of Biological Chemistry, 293(51), 19511-19521. DOI: 10.1074/jbc.RA118.005421

Sastry, M. S., Korotkov, K., Brodsky, Y. \& Baneyx, F. (2002). Hsp31, the Escherichia coli yedU gene product, is a molecular chaperone whose activity is inhibited by ATP at high temperatures. Journal of Biological Chemistry, 277(48), 46026-46034. DOI: 10.1074/jbc.M205800200

Sastry, M. S., Quigley, P. M., Hol, W. G. \& Baneyx, F. (2004). The linker-loop region of Escherichia coli chaperone Hsp31 functions as a gate that modulates high-affinity substrate binding at elevated temperatures. Proceedings of the National Academia of Sciences of the United Estates of America, 101(23), 8587-8592. DOI: 10.1073/ pnas.0403033101

Segal, N. \& Shapira, M. (2015). HSP33 in eukaryotes - an evolutionary tale of a chaperone adapted to photosynthetic organisms. The Plant Journal, 82(5), 850-860. DOI: 10.1111/tpj.12855

Seit-Nebi, A. S. \& Gusev, N. B. (2009). Versatility of the small heat shock protein HSPB6 (Hsp20). Cell Stress and Chaperones, 15(3), 233-236. DOI: 10.1007/s12192-0090141-x

Skoneczna, A., Kaniak, A. \& Skoneczny, M. (2015). Genetic instability in budding and fission yeast-sources and mechanisms. FEMS Microbiology Review, 39(6), 917-967. DOI: $10.1093 /$ femsre/fuv028

Sluchanko, N. N., Beelen, S., Kulikova, A. A., Weeks, S. D., Antson, A. A., Gusev, N. B. \& Strelkov, S. V. (2017). Structural basis for the interaction of a human small heat shock protein with the 14-3-3 universal signaling regulator. Structure, 25(2), 305-316. DOI: 10.1016/j.str.2016.12.005

Srivastava, S. K., Lambadi, P. R., Ghosh, T., Pathania, R. \& Navani, N. K. (2014). Genetic regulation of spy gene expression in Escherichia coli in the presence of protein unfolding agent ethanol. Gene, 548(1), 142-148. DOI: 10.1016/j.gene.2014.07.003

Suss, O. \& Reichmann, D. (2015). Protein plasticity underlines activation and function of ATP-independent chaperones. Frontiers in Molecular Biosciences, 2(43), 1-10. DOI: 10.3389/fmolb.2015.00043

Tsai, C-J., Aslam, K., Drendel, H. M., Asiago, J. M., Goode, K. M., Paul, L. N., Rochet, J-C. \& Hazbun, T. R. (2015). Hsp31 is a stress response chaperone that intervenes in the protein misfolding process. Journal of Biological Chemistry, 290(41), 24816-24834. DOI: 10.1074/jbc.M115.678367

Usami, Y., Hatano, T., Imai, S., Kubo, S., Sato, S., Saiki, S., Fujioka, Y., Ohba, Y., Sato, F., Funayama, M., Eguchi, H., Shiba, K., Ariga, H., Shen, J. \& Hattori, N. (2011). DJ-1 associates with synaptic membranes. Neurobiology of Disease, 43(3), 651-662. DOI: 10.1016/j.nbd.2011.05.014

van de Klundert, F. A., Smulders, R. H., Gijsen, M. L., Lindner, R. A., Jaenicke, R., Carver, J. A. \& de Jong, W. W. (1998). The mammalian small heat-shock protein Hsp20 forms dimers and is a poor chaperone. European Journal of Biochemistry, 258(3), 1014-21. DOI: 10.1046/j.14321327.1998.2581014.X

Verschuure, P., Croes, Y., van den IJssel, P. R., Quinlan, R. A., de Jong, W. W. \& Boelens, W. C. (2002). Translocation of small heat shock proteins to the actin cytoskeleton upon proteasomal inhibition. Journal of Molecular and Cellular Cardiology,34(2), 117-128. DOI: 10.1006/jmcc.2001.1493

Vogt, S. L. \& Raivio, T. L. (2012). Just scratching the surface: an expanding view of the Cpx envelope stress response. FEMS Microbiology Letters, 326(1), 2-11. DOI: 10.1111/j.15746968.2011.02406.x

Vos, M., Kanon, B. \& Kampinga, H. (2009). HSPB7 is a SC35 speckle resident small heat shock protein. Biochimica et Biophysica Acta, 1793(8), 1343-1353. DOI: 10.1016/j. bbamcr.2009.05.005

Voth, W. \& Jakob, U. (2017). Stress-activated chaperones: a first line of defense. Trends in Biochemical Sciences, 42(11), 899-913. DOI: 10.1016/j.tibs.2017.08.006

Webster, J. M., Darling, A. L., Uversky, V. N. \& Blair, L. J. (2019). Small heat shock proteins, big impact on protein aggregation in neurodegenerative disease. Frontiers in Pharmacology, 10(1047), 1-18. DOI: 10.3389/fphar.2019.01047

Weeks, S. D., Baranova, E. V., Heirbaut, M., Beelen, S., Shkumatov, A. V., Gusev, N. B. \& Strelkov, S. V. (2014). 
Molecular structure and dynamics of the dimeric human small heat shock protein HSPB6. Journal of Structural Biology, 185(3), 342-354. DOI: 10.1016/j.jsb.2013.12.009

Wei, Y., Ringe, D., Wilson, M. A. \& Ondrechen, M. J. (2007). Identification of functional subclasses in the DJ-1 superfamily proteins. PLoS Computational Biology, 3(1), 120-126. DOI: 10.1371/journal.pcbi.0030010

Won, H. S., Low, L. Y., Guzman, R. D., Martinez-Yamout,
M., Jakob, U. \& Dyson, H. J. (2004). The zinc-dependent redox switch domain of the chaperone Hsp33 has a novel fold. Journal of Molecular Biology, 341(4), 893-899. DOI: 10.1016/j.jmb.2004.06.046

Wu, K., Stull, F., Lee, C. \& Bardwell, J. C. (2019). Protein folding while chaperone bound is dependent on weak interactions. Nature Communications, 10(1), 4833. DOI: 10.1038/s41467-019-12774-6 